5. Ramos MJ, Esteban J, Jimenez Asensio M, Soriano F. Tuberculosis extrapulmonar. Experiencia en un hospital general (1980-1993). Rev Clin Esp 1995; 195: 546-549.

6. Auerbach O. Acute Generalized Miliary Tuberculosis. Am J Pathol 1 944; 20: 121-136.

7. Garrido G, Gómez-Reino JS, femández Dapica P, Palenque E, Prieto S. A review of Peripheral tuberculous Arthritis. Semin Arthritis Rheum 1988; 178: 142-149.

\section{Episodios paroxísticos simpáticos secundarios a anoxia cerebral}

\section{Sr. Director:}

En la literatura médica se recoge un cuadro clínico descrito como "ataques diencefálicos" o "crisis paroxísticas simpáticas" que cursa de forma episódica con hiperactividad simpática y posturas extensoras en pacientes con disminución del nivel de conciencia. Consideramos que es importante saber reconocerlo clínicamente para evitar pruebas diagnósticas innecesarias y poder manejarlo de forma adecuada, sobre todo si se tiene en cuenta que, en muchas ocasiones, se presenta en pacientes que son únicamente subsidiarios de medidas paliativas.

Aportamos el caso de un varón de 29 años adicto a drogas por vía parenteral con antecedentes personales de hepatitis por virus $\mathrm{C}$ que ingresa en situación de parada respiratoria, con intensa cianosis y signos de venopunción reciente. Tras poner tratamiento con naloxona y flumazenil sin revertir el cuadro se procede a intubación endotraqueal y conexión a ventilación mecánica. En la exploración física el paciente presentaba un Glasgow de 4, pupilas mióticas y arreactivas, con reflejos corneales y de tronco presentes y tetraparesia. El resto de la exploración fue normal, sin signos traumáticos. A los 15 días del ingreso presentaba desconexión respecto al medio circundante, nula respuesta verbal, apertura ocular espontánea y tetraparesia de extremidades (e. superior izda espástica y derecha hipotónica y ambas extremidades inferiores en hiperextensión). Se le realizó gastrostomía y traqueostomía, retirando la ventilación mecánica con conexión a oxígeno con tubo en T. En la analítica inicial destacaba positividad para tóxicos en orina (opiáceos, cannabis, cocaína y benzodiacepinas), siendo la analítica de sangre y las pruebas de imagen normales (RX tórax, abdomen y cráneo). El TAC craneal mostraba una ligera atrofia cortical, sin focos isquémicos o hemorrágicos ni dilataciones ventriculares. A partir del $7^{\circ}$ día tras el ingreso comenzó a presentar diariamente episodios de duración variable, desde 2 o 3 minutos a varias horas, consistentes en hipertermia de 39- $40^{\circ}$, taquicardia con frecuencia cardiaca entre 130-150 latidos/minuto, taquipnea de 20 respiraciones/minuto, hipersudoración y postura de rigidez en hiperextensión de las cuatro extremidades con rotación interna de miembros superiores, sin objetivarse variaciones significativas de las cifras de tensión arterial. Su número era variable, llegándose a los 20 diarios. Durante los episodios se realizaron hemocultivos repetidos, con resultados negativos, y varios electroencefalogramas, sin demostrar actividad epileptiforme. Asimismo se realizó un nuevo TAC craneal en el que no se objetivaron lesiones ni signos de hidrocefalia. No se apreciaron factores desencadenantes. Dichos episodios fueron yugulados inicialmente con dosis repetidas de midazolam, pero reaparecían al disminuirlas, destacando la nula respuesta a la terapéutica con difenilhidantoína y a los antitérmicos. A partir de las tres semanas se comienza el tratamiento con dosis repetidas de $5 \mathrm{mg}$. de cloruro mórfico, disminuyendo el número y la duración de los episodios y posteriormente se asoció propanolol . Sin embargo, para llegar a su total control fueron requiriéndose dosis progresivamente ascendentes de cloruro mórfico, probablemente por un fenómeno de tolerancia en relación a su drogadicción, hasta alcanzar los $2.400 \mathrm{mg} /$ día en perfusión continua endovenosa asociados a propanolol $(60 \mathrm{mg} / 8 \mathrm{~h})$. Cualquier intento de reducir la dosis de cloruro mórfico conllevaba un aumento en la frecuencia de las crisis.

Un cuadro clínico que cursa con episodios de alteración de la temperatura corporal, taquicardia, taquipnea, hipertensión, sudoración profusa, sialorrea y posturas de rigidez en hiperextensión en pacientes con disminución del nivel de conciencia ha sido descrito en varios trastornos del sistema nervioso central (1). Su etiopatogenia no está clara y, aunque se propuesto una hipótesis epileptógena como explicación, en la mayoría de estos pacientes no se ha demostrado actividad epiléptica durante las crisis ni ha habido respuesta a terapias anticonvulsivantes. La estructura implicada en la génesis de este proceso es el diencéfalo, por lo que en la literatura se ha descrito con diversos nombres, entre los que destacan "ataques diencefálicos" o "epilepsia diencefálica" $(2,3)$, y hay autores que sugieren también una lesión en el tronco encefálico, por lo que prefieren denominarlos trastornos paroxísticos simpáticos. Se cree que existe una hiperactividad simpática y Bullard $(3,4)$ propone que su mecanismo sería un fenómeno de liberación a nivel del diencéfalo y porción superior del tronco secundario a la pérdida del control cortical o subcortical. Este cuadro se ha presentado asociado a diversas patologías como la agenesia de cuerpo calloso, hidrocefalia, traumatismos craneoencefálicos, tumores diencefálicos y supraselares. En la mayoría de los casos se ha demostrado alguna lesión en diencéfalo o tronco, sin embargo Boeve describe un caso secundario a traumatismo craneoencefálico en el que no se objetiva ninguna lesión a dichos niveles (1).

En nuestro caso tampoco se descubrieron mediante TAC ni lesiones intracraneales ni signos de hidrocefalia. Asimismo los EEG realizados durante los episodios no demostraron focos epileptógenos ni hubo respuesta al tratamiento con fenitoína. Los hemocultivos realizados coincidiendo con los picos febriles durante las crisis no mostraron crecimiento. En aquellos casos en los que no haya posibilidad de actuación sobre el proceso causal (resección quirúrgica de tumores, shunts ventriculares...) el tratamiento de elección es la morfina, que puede utilizarse de forma aislada o asociada a otros fármacos como bromocriptina o betabloqueantes $(1,3,5)$. En la literatura revisada el control mayor de los síntomas se consigue con morfina, sin embargo se describe un caso en el que se utiliza la clonidina de forma aislada (6). Otros fármacos que pueden tener utilidad en el manejo de esta patología son el midazolam y el clonacepam.

\section{Repiso Moreno, Ma S. Casis Navajas, J. L. Peña Somovi- lla, F. Jiménez Bermejo}

Servicio de Medicina Interna. Complejo Hospitalario San Millán-San Pedro. Logroño

1. Boeve B, Wijdicks E, Benarroch E, Schmidt K. Paroxysmal Sympathetic Storms ("Diencefalic Seizures") after severe diffuse axonal head injury. Mayo Clin Proc 1998; 73: 148-152.

2. Morris H. Sudden diencephalic events. Annals of Neurology 1998; 23: 208.

3. Bullard D. Diencephalic seizures: responsiveness to bromocriptine and morphine. Ann Neurol 1987; 21: 609-611.

4. Rossitch E Jr, Bullard D. The autonomic dysfunction syndrome: aetiology and treatment. Br J Neurosurg 1988; 2: 471-478.

5. Talman WT, Floreck G, Bullard D. A hyperthermic syndrome in two subjects with acute hydrocephalia. Arch Neurol 1988; 45: 1037-1040.

6. Goh K, Conway E, DaRosso R, Muszynski C, Epstein F. Sympathetic storms in a child with a midbrain glioma: a variant of diencephalic seizures. Pediatr Neurol 1999; 21: 742-744. 